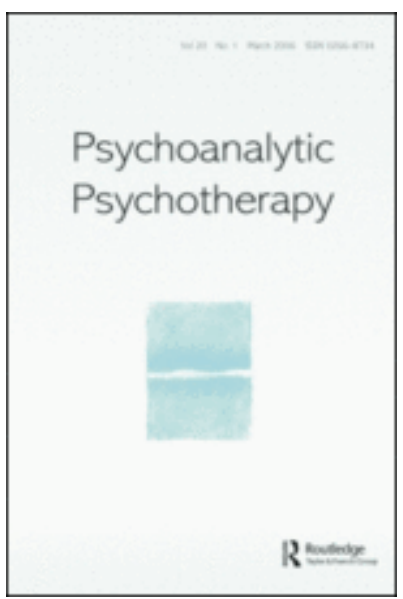

\title{
Living with dementia: Using mentalization-based understandings to support family carers
}

\begin{tabular}{|r|l|}
\hline Journal: & Psychoanalytic Psychotherapy \\
\hline Manuscript ID & RPPS-2019-0008.R1 \\
\hline Manuscript Type: & Original Article \\
\hline Keywords: & Dementia, Family carers, Mentalization, Emotional support \\
\hline \multicolumn{2}{|l}{} \\
\end{tabular}

\section{SCHOLARONE ${ }^{m}$ Manuscripts}




\title{
Living with dementia: Using mentalization-based understandings to support family carers
}

\begin{abstract}
The number of people living with dementia is rising due to the aging of the population. Nearly two thirds of people with dementia live at home and the majority of the emotional and practical support that they receive is provided by family carers. Psychodynamic perspectives provide a valuable framework of understanding from which to consider the emotional dimensions of caring for a family member who is living with dementia. This paper offers a further contribution to this emerging field of knowledge by discussing the impact that mentalizing and non-mentalizing states of mind may have on the dynamics of the relationship between a person with dementia and their family carers. The potential benefits of using mentalization-based understandings are illustrated by four case vignettes. The vignettes are taken from a communication skills training course for family carers called Empowered Conversations and a web-based support initiative called Empowered Carers, which is targeted at family carers who provide intensive support for people living with dementia in their own homes.
\end{abstract}

\section{Keywords}

Dementia, Family carers, Mentalization, Emotional support 


\section{Introduction}

Dementia is an umbrella term used for a range of neurodegenerative disorders that through their affect upon brain infrastructure and cognitive reserve progressively impair the ability to lay down new memories, think through plans and communicate understanding to others. Dementia also affects sensory perception, physical co-ordination and the ability to live a functionally independent life (Prince et al., 2013). The number of people living with dementia is rising due to the aging of the population, although dementia is not exclusive to old age (World Health Organisation, 2012). Life expectancy for people with Alzheimer's disease, the most common type of dementia can be up to twenty years (Tom et al., 2015). Nearly two thirds of people with dementia live at home and the majority of the emotional and practical support that they receive is provided by family carers (Luengo-Fernandez et al., 2010).

Living with dementia can be a positive experience if a person has a meaningful life and can maintain a sense of security, continuity and belonging (Birt et al., 2019) However, the challenges are considerable. People with dementia face huge uncertainty, as they absorb the emotional impact of living a stigmatised identity, the fragmentation of their sense of self and losing their independence as they approach the end of life (Sabat 2009, Piiparinen \& Whitlatch 2011).

Family carers provide high levels of practical assistance, whilst adjusting to the changes in their relationship (Feast et al., 2016) as the person with dementia experiences neurological decline. Caring for a family member with dementia can be a source of personal fulfilment, evoking feelings of relational bonding and satisfaction related to the fulfilment of one's duty 
of care (Roth et al., 2015; McCormack et al., 2017). However, the interplay between their changing relational roles and caregiving responsibilities can cause carers to feel socially isolated and under-valued (Gallagher \& Rickenbach, 2019). The sense of entrapment and guilt many carers experience is compounded by the difficulties of negotiating the transition from being a companion, confidant and lover of a partner to having an asymmetric, dependent relationship (Santulli \& Blandin, 2015) or role reversal in the case of children caring for parents. Troubled aspects of their shared history can also surface as repressed feelings come to the fore, as carers manage distressing behaviours and find little time for themselves (Chen \& Bailey, 2018). Together, these pressures contribute to the increased risk of depression, anxiety and poor physical health among family carers of people with dementia (de Vugt \& Verhey, 2013; Hiel et al., 2015). External assistance such as access to social amenities and respite care enhances carer resilience (Feast et al., 2017; Tschanz et al., 2013), but research indicates that this support needs to be augmented by education and emotional support if it is to have a sustainable impact (Feast et al., 2016; Parkinson et al., 2016).

Psychodynamic perspectives provide a valuable framework of understanding from which to consider the emotional dimensions of caring for a family member who is living with dementia. A central element of this understanding is the recognition that people with dementia and their carers have emotional and relational needs that are different, but interlinked and that these needs cannot be fully separated out using the binary terms of having dementia, of not having dementia. There is an 'underdeveloped space between our cognitions and our emotional understanding' that often lends more common ground between those who are living with dementia and their carers than is commonly 
acknowledged. All of us have the tendency to be disturbed by primitive anxieties and the urge to hold on to certainties in the face of loss (Garner, 2004). The relational dynamics of people living with dementia and other family members varies not only according to the type and stage of dementia (Evans, 2008), but through the expression of their fears. For example, people living with vascular dementia may have more insight into the deterioration of their cognitive functioning than someone in the early stages of Alzheimer's Disease. However, their subjective response to the loss of cognitive resources and increasing dependence on others is likely to be influenced by a diverse range of factors including their individual motivations and wishes, the availability of good internal objects (Loboprabhu et al., 2007) and carers who are attuned to their current emotional needs (Malloy, 2009).

For family carers it can be especially difficult to work through feelings of loss, grief and burden, as the abilities, personality and relationship with their spouse, parent or sibling irrevocably change (Blandin \& Pepin, 2017). Psychodynamic practitioners such as Balfour (2006), Davenhill (2007), Evans (2008) and Cairns (2012) have highlighted the powerful transference and countertransference reactions that are stirred up by unresolved loss. They point to the tendency there can be to emotionally close down or act out feelings in unreflective ways. In their more serious forms the projection of these negative feeling states can lead to the abuse of people with dementia, as carers act out their frustrations and exploit assymmetries of power (Cooper, 2009).

This paper offers a further contribution to this emerging field of knowledge by discussing the impact that mentalizing and non-mentalizing states of mind may have on the dynamics 
of the relationship between a person with dementia and their family carers. The potential benefits of using mentalization-based understandings are illustrated by four case vignettes. The vignettes are taken from a communication skills training course for family carers called Empowered Conversations (http://empowered-conversations.co.uk/) and a web-based support initiative called Empowered Carers, which is targeted at family carers who provide intensive support for people living with dementia in their own homes.

\section{Mentalization}

Bateman \& Fonagy (2010, p. 11) defined mentalization as "the process by which we make sense of each other and ourselves, implicitly and explicitly, in terms of subjective states and mental processes." A mentalizing stance requires us to be curious and refrain from acting on the automatic assumptions that we know what another person is thinking from the basis of our own experience. Mentalization plays a key role in the reading of social cues, as it enables us to locate where the thoughts and feelings of the other person may be coming from (Reddy, 2008; Shai \& Fonagy, 2014). It is a state of mind that can enhance our ability to respond flexibly to changing interpersonal circumstances (Fonagy et al., 2002) and sustain 'negative capability'; the capacity to live with uncertainty and anxieties of which are largely unconscious (Bion, 1970).

Although mentalization-based approaches (Fonagy et al., 2002) are most commonly used to work with people identified as having a personality disorder (Bateman \& Fonagy, 2010), their use has been extended to common mental health problems (Lemma et al., 2011) and to social issues such as the support of families in crisis (Asen \& Fonagy, 2017). The rationale for using mentalization based understandings with family carers of people with dementia is 
that it may help by opening up three channels of communication (Bateman et al., 2017) that support emotional resilience.

Communication channel one relates to the provision of a framework of understanding that can help family carers explore their experiences and states of mind.

Communication channel two is a space that enables carers to pause, reflect and reconnect with their ability to mentalize about their own state of mind and the state of mind of the person with dementia, which may have been temporarily lost.

Communication channel three - is an environment that can sustain the capacity to mentalize during the course of what may be a long and tumultuous emotional journey.

Mentalization is supported within the context of an emotional environment in which it is safe to reflect upon our internal experiences and explore our affective response, in the presence of someone who is accepting of our vulnerabilities and attuned to our aspirations (Fonagy \& Allison, 2016). This was illustrated by the anthropologist Janelle Taylor (2009) who gave a highly personal and moving account of how she grieved for the place she had lost in her mother's mind. Taylor was able to process the catastrophic impact that dementia had upon her relationship with her mother and take solace from the meaningful moments that they were able to share (Stern, 2004). The variability of her mother's cognitive functioning, which provided fleeting glimpses of what had been and what might have been, evoked conscious and unconscious emotional reactions that made this a bitter-sweet experience. 
'My mother would certainly fail a pop quiz about my name, but she lights up when she sees me. She is eager to talk, and tries to speak, but words often elude her, and sentences get distracted and wander off in unanticipated directions. The difficulties of talking don't seem to bother her terribly though. There is pleasure in it still' (Taylor, 2009 p326).

Taylor captures many of the key qualities associated with being able to sustain a mentalizing state of mind. She developed a greater tolerance of her own vulnerabilities and selfacceptance of the negative feelings that she harboured towards her mother, as a daughter/care partner. This helped her to sustain her deep love for her mother, which her mother reciprocated until the end of her life.

\section{Non-Mentalizing States of Mind}

The capacity to mentalize is vulnerable to disruption as we encounter painful realities (Boulanger, 2011). It is particularly difficult to mentalize when experiencing powerful emotions such as anxiety, distress, grief or anger, all of which are common amongst care partners. There are three axiomatic non-mentalizing states of mind; psychic equivalence, pretend thinking and teleological reasoning (Fonagy et al., 2002). These non-mentalizing states of mind are not mutually exclusive and they can be adaptive forms of defence, but if they grow into rigidly held positions, they may contribute to a closed and persecuted mindset that is difficult to work through.

Psychic Equivalence 
Psychic equivalence is a non-mentalizing state of mind in which our emotional feelings are experienced as external reality. In a state of psychic equivalence our felt experience is all encompassing.

\section{Pretend Thinking}

Pretend thinking is a form of defence against realities that are too much to bear and an unconscious investment in not seeing things differently. Imaginative thoughts take precedence and become detached from underlying realities.

\section{Teleological Reasoning}

Teleological reasoning looks at ostensible behaviour as an end goal without taking account of the situational context and different motives that may lay behind the behaviour (Allen et al., 2008).

Family carers who can maintain a mentalizing stance may be more able to respond in empathic, person-centred ways to relatives living with dementia. Mentalizing may enhance the ability to provide personalised care in a nuanced and differentiated way (Kitwood \& Bredin, 1992). On the other hand, non-mentalizing responses may be a root cause of misunderstanding and emotional disengagement, whilst dealing with changing relational parameters and 'unknown unknowns.' For example, this type of mindset can be problematic when carers automatically attribute challenging behaviours to permanent changes in the personality of the person with dementia, without acknowledging the emotional losses and challenges they experience (Feast et al., 2016). The differences between non-mentalizing and mentalizing states of mind are summarised in Table 1. 


\section{Empowered Conversations}

Empowered Conversations is a communication skills training course that is designed to open up new avenues for engagement between people with dementia and their families by helping to work around barriers to communication. The goal is to foster the ability of carers to reflect upon their communicative interactions, so that they can support their relatives with dementia in less reactive, more responsive ways. In order to achieve this goal, it is essential for carers to pay attention to the pragmatics of communication, as well as an experiential understanding of what may be happening for the person with dementia (Wray, 2016; Morris et al., 2018). Attending to the pragmatics of communication such as the worries carers may have about saying the right thing, provides a safe entry point for carers to reflect upon their experiences. Reflecting upon the experience of the person with dementia links more explicitly with the process of mentalization, as carers are given a space to take a step back, pause and emotionally connect with the person with dementia in the context of a small group settings with other carers who are in similar positions to themselves.

The course themes include:

a) What it is like to talk to someone with dementia and what might it feel like for a person with dementia to talk to us?

b) An exploration of the pragmatic and emotional barriers that inhibit conversational interaction;

c) The demonstration of strategies that assist in promoting conversational interaction with people who are living with dementia; 
d) An examination of how we communicate 'without talking';

e) A reflection upon situational encounters where conversational strategies are used in practice;

f) A review of the lessons learnt from the course and a celebration of successful stories of change that have led to beneficial outcomes.

\section{Jenny and Her Mum}

Jenny's story (McEvoy \& Bellass, 2017) highlights how the ability to mentalize may be supported by reflective exercises in small group settings. In the first part of a session about the ways in which we communicate without talking, the participants were asked to comment upon the associations they made with a cartoon drawn by Tony Husband (2014) who has written a book about the impact of his dad's dementia. The participants were then invited to draw their own cartoon if they wanted to. Jenny sketched a scene from a typical weekend when she stayed with her mum who lived in a different region of the country (see Figure 1.) Jenny talked about the meaning of the sketch for her. In the sketch Jenny was looking towards the television, whilst she was ironing. Jenny had not been consciously aware of having her back to her mum beforehand and was embarrassed that this was the case. The dialogue in the speech bubbles further reinforced her sense of disconnection. Jenny says 'Are you drinking your coffee, Mum?' and her mum responds by saying 'Where is it?' Jenny wondered aloud about whether the neat pile of ironing symbolised her desire to create a feeling of order and control, which contrasted with the lack of control that she felt about her mum's dementia. "I can't stand the mess around her chair. I don't want to look at it. Mum keeps asking me for things all day. I do the ironing to try and give myself a bit of peace and quiet." 
Jenny linked the dynamic that was captured in the sketch to subliminal feelings that were stirred up from her childhood. As a child she resented being over-controlled by her mum and had sought out protected spaces where she did not feel intruded upon. The other participants in the group expressed their understanding of her position, having had similar experiences themselves. This seemed to quell Jenny's frustration about her sense of entrapment and opened up space for her to think about her response to her mum's vulnerability. "If I turned myself around, we could have more conversation and she could probably pass me the clothes. It's just a little thing but it might actually make her feel like she's involved. She's always been houseproud and she used to enjoy doing the ironing."

When Jenny returned to the course the following week she shared her story of change. Turning the ironing board around and switching the television off, had made a major difference to the quality of her conversational interaction with her mum. They did the ironing together and Jenny had a longer, more varied and engaged conversation with her mum than she had had for many months. Afterwards, her mum was calmer and made fewer claims upon Jenny's attention. Having access to a quieter state of mind and not being so immersed in a state of psychic equivalence had enabled Jenny to reach out to her mum and her mum had engaged with her in a positive way, as perhaps she felt the safety and connection with Jenny that she had been craving for.

\section{Clara and Susan}

In a review of the lessons learnt from the Empowered Conversations course Clara spoke about how she had often felt irritated with her partner Susan, as they got prepared to go 
out. Clara was a punctual person who disliked being late, whereas Susan, who did not like to be rushed had always been much more relaxed about running over time. The tensions they encountered had escalated recently as Susan had become upset by Clara's frequent prompts to hurry up. Clara reflected that Susan was finding it harder to sequence her actions, as her concentration and short term memory was fading and did not want Clara to do things for her that she could do for herself. Clara felt guilty about not being more patient with Susan. Voicing her impatience within the group helped Clara to recognise that times when they were getting ready to go out were trigger points for the expression of her more general worries and frustrations. "After all," she said, "the staff at the day centre are not going to get upset if we are late." Being punctual remained important to Clara, but her increased ability to mentalize enabled her to empathise with Susan's difficulty in getting ready to go out at a set time. There was a shift in her mindset and communications with Susan, as she focused instead upon the ways in which she could help Susan to get ready without pressuring her to rush. Clara laid out Susan's clothes where she could easily find them. She talked about other things as she got ready to go out and was more able to she set her annoyance aside when time overran. Yet, despite her best efforts, Clara acknowledged that her impatience with Susan could still be problematic. It was hard to break the habits of a lifetime.

\section{Empowered Carers}

Empowered Carers is a carer support initiative based on the New York University Caregiver Intervention (NYUCI) (Gaugler et al, 2011; Mittelman, et al, 2004). The aim of the initiative is to provide a holding environment that sustains the emotional resources of the family 
caregivers and thus enable them to stay connected to the person with dementia. After an initial face to face meeting with the main carer in their own home or place of their choice, ongoing support is offered via an online video-conferencing platform that can be accessed by smart phone, tablet or laptop computer. Although the developers of the NYUCl do not use the language of mentalization, we can speculate that the provision of structured support for family carers enhances their ability to respond flexibly to their changing circumstances and increase the capacity of carers to reflect upon the differing emotional responses they have to their situation as carers. This may allow carers to work through ambiguous loss and consider the wishes and needs of the person with dementia within their changing relationship.

\section{Mark and Laura}

Mark was highly stressed. His wife Laura was in the middle stage of dementia and was losing many of her functional capabilities. She often cried and was visibly distressed. An intensely proud, loyal and caring man, Mark maintained an outward appearance of joviality but he was inwardly distressed, as he felt her pain. He missed Linda's companionship, the long conversations they had in the past and the active social life they had enjoyed together with their friends and extended family. He felt that things were spiralling out of his control, Linda's behaviour was difficult to understand and he was depressed when he thought about their future. In his weekly sessions with his dementia care worker he talked about these challenges and mourned for the life with Laura that he was losing. 
"I don't like talking about things with friends or family and I don't want to most of the time. I like to talk to you. This is my support. I do everything jokingly you know that. I speak to my sister but they are too closely involved."

The dementia care worker adopted a not knowing stance, asking questions such as, 'How do you think that Laura might be feeling?' and 'What makes you say that?' as she gently encouraged Mark to pay attention to the effect that Linda's different emotional states had upon him. As a result, Mark began to talk more freely about the frustration he felt as Laura lost her independence and relied upon him to do basic tasks for her. There was a shift as Mark moved from the unmentalised state of psychic equivalence in which his experience was all encompassing, to a less persecutory mentalizing stance in which he could identify his own frustrations and his concern about Linda's state of mind without being so overwhelmed.

"I was trying to do the monitoring of Laura being weepy and it was all too much. I was trying to analyse it all. It doesn't matter now because I know and understand. The other day she was upset... Perhaps it's more than just the dementia. She was upset and wanted her mum. And I said, 'What do you want you mum for?' And she said, 'A hug'. So I gave her a hug and she gave me a big hug back and she cheered up."

Mark saw Linda's tearfulness primarily as a sign of her craving for the emotional security and protection that was embodied, for her, in her mother's embrace. However, as Mark reflected upon his experience another layer of meaning emerged in Laura's response. Laura gave him a big hug back that lifted Mark's spirits and reinforced the continuity of their 
shared experience. Laura's response to Mark's embrace underscores a point eloquently made by Ramsay-Jones (2015; 2019); despite their cognitive decline, many people with dementia retain a level of emotional sensitivity that is higher than is generally appreciated. This awareness may be most apparent in their unconscious communications about their salient concerns. Laura's awareness of who Mark was was slipping, but she was still sensitive to his emotional needs.

\section{Charles and Dorothy}

Charles cared for his mum Dorothy full time at home. In the week prior to his first session with his dementia care worker he had only left the house they shared twice. On both occasions he had nipped out of the house for a few minutes to shop next door whilst Dorothy was asleep. The assistant in the shop was the only person he had spoken to other than Dorothy that week. Charles recognised that he was becoming increasingly isolated but felt guilty about spending time away from Dorothy who was unstable on her feet and needed assistance with her personal needs. The youngest child of a large family, Charles had fallen out with his siblings and had stopped speaking to them.

The transcript below is taken from one of his first sessions with his dementia care worker. Charles: Well I'm putting in for respite care you know. That's it. Dorothy: Putting me into respite? [Dorothy had previously had a negative experience in respite care].

Charles simultaneously squelches up his face and crunches up his body as Dorothy speaks as though to say, 'What have I just said?' 
Charles: Mum this is for me not you. [Turning away from screen and looking towards his mum he shouts loudly in an irritable tone of voice.]

Charles: You have to be like that sometimes. [Turns back towards screen.]

Dementia Care Worker: So you understand that you need that break.

Charles: Ye. And I think that a lot of the other people outside.. you know the professionals in.. they see that too.

Dementia Care Worker: It's important that you get that time to recharge your batteries. Charles: Of course it is.

Dementia Care Worker: Otherwise care becomes a struggle.

Charles: I tried to explain it in a thousand different ways to my mum but there's no way of getting it through..

The Dementia Care Worker patiently listened to Charles as he expressed his frustrations and reflected back the need to take a break. She held back from giving him direct advice as to what to do and allowed him to question himself. Her understanding presence helped to facilitate a shift in his mindset as Charles implicitly recognised that his unmentalised state of pretend thinking - the notion that he could carry on as he was doing - was disconnected from the reality of the situation. There was a significant change in his mindset as he recognised where his thoughts and feelings were coming from - feelings of protectiveness towards Dorothy, difficulty coming to terms with the loss of his own independence, anger towards his siblings whom he felt abandoned by - without shying away from their implications.

After a few weeks of talking through these issues Charles accepted that it was counterproductive to defensively block out his anger and grief by soldiering on in the way 
that he had been. He contacted his siblings, talked through some of the issues that had brought them into conflict and accepted their support. He also discussed alternative ways of dealing with the fears that Dorothy had voiced about respite care. In the transcript below he spoke to the dementia care worker about the improvement in his mood and the new sense of freedom he had. This shift was symbolised by the metaphor of a bike, which Charles had bought from his brother and was looking forward to riding. Charles: I'm doing al'right. I've just got a new bike. Well, I've not. I've bought it from my brother. There it is. [Moves camera to show the dementia care worker his bicycle.] Dementia Care Worker: Wow. What are you going to with that? Charles: I'm going to ride it when I can. Dementia Care Worker: Good for you.

\section{Conclusion}

In this paper, we have outlined the case for using mentalization-based understandings to support the family carers of people living with dementia. Family carers are particularly susceptible to stress and depression, not only due to the practical demands of caring but also the emotional challenges of dealing with the losses and emotional adjustment involved in supporting their spouses, parents and siblings who have declining cognitive capabilities. Mentalization provides a point of orientation that gives an insight into the channels of communication that may be helpful in enhancing the emotional resilience of care partners who are at high risk of 'burnout' due to their caregiving responsibilities and the struggle to sustain their relationship with the person with dementia (Richardson et al., 2013). 
The case vignettes in the paper highlighted the potential benefits of using mentalizationbased understandings to support family carers. The reflective exercise that Jenny engaged in on the Empowered Conversations Course helped her to talk through her grief about her mum's dementia and the impact it was having on their relationship. Clara was able to voice her frustrations in the Empowered Conversations course and let go of her teleological focus than mandated that Susan be ready on time. As a consequence she was more patient with Susan and felt less guilty about the inadequacy she felt as her primary carer. The moving story of Mark and Laura from the Empowered Carers project illustrates how many people with dementia retain a level of emotional sensitivity that is higher than is generally appreciated. Linda's awareness of who Mark was was slipping, but she was still sensitive to his emotional needs as she warmly embraced him. Charles was locked into the rigid mindset of pretend thinking - the notion that he could carry on as he was doing in caring for Dorothy as the demands he was placing upon himself were becoming impossible to manage. Having the opportunity to talk through his experience with a dementia care worker from outside of the family helped to shift the frame of his state of mind, from a persecuted mindset to a mindset in which he was more accepting of his own vulnerabilities and dependency needs.

Enhancing the capacity to mentalize may help to increase the emotional resilience of family carers via the pathways outlined in Table 2, but empirical research is needed to test out this hypothesis. The Empowered Conversations communication skills course is currently being evaluated in a mixed methods feasibility study. The Empowered Carers initiative is modelled on the New York University Caregivers Intervention (NYUCI) and incorporates mentalization based understandings. Longitudinal studies have identified that the NYUCl enhances the social functioning of the person with dementia and mental health of family carers. It is also 
seen as cost effective as it delays the transition into nursing home accommodation by an average of 557 days (Mittelman et al., 2006; Long et al., 2014). However, the active ingredients of the intervention, which may include an enhanced ability to mentalize have yet to be fully explicated. 


\section{References}

Allen, J., Fonagy, P., \& Bateman, A. (2008) Mentalizing in clinical practice Washington: American Psychiatric Press.

Asen, E. \& Fonagy, P. (2017) Mentalizing family violence part 1: Conceptual framework. Family Process, 56(1): 6-21.

Balfour, A. (2006) Thinking about the experience of dementia: the importance of the unconscious. Journal of Social Work Practice. 20 (3): 329-346.

Bateman, A., Campbell, C., Luyten, P., \& Fonagy, P. (2017) A mentalization-based approach to common factors in the treatment of borderline personality disorder. Current Opinion in Psychology 21: 44-49.

Bateman, A., \& Fonagy, P. (2010) Mentalization-based treatment for borderline personality disorder. World Psychiatry 9(1): 11-15.

Bion, W. R. (1970) Attention and interpretation. London: Tavistock Publications.

Birt, L., Griffiths, R., Charlesworth, G., Higgs, P., Orrell, M., Leung, P., \& Poland, F. (2019). Maintaining social connections in dementia: a qualitative synthesis. Qualitative Health Research doi: 1049732319874782.

Blandin, K. \& Pepin, R. (2017) Dementia grief: A theoretical model of a unique grief experience. Dementia: The International Journal of Social Research and Practice 16(1): 6778.

Boulanger, G. (2007) Wounded by reality: Understanding and treating adult onset trauma. NJ: Analytic Press. 
Cairns, M. (2012) In sickness and in health: an exploration of some of the unconscious processes involved in the decision by family caregivers to place a family member with dementia in residential care. Psychoanalytic Psychotherapy 26(1): 34-47.

Chen, C.K., \& Bailey, R.W. (2018) Episodic memories of relationship quality, procedural knowledge of attachment scripts, and the experience of daughters caring for a parent with dementia. Dementia: The International Journal of Social Research and Practice 17(1): 61-77.

Cooper. C., Selwood, A., Blanchard, M., Walker, Z., Blizard, R. \& Livingston G. (2009) Abuse of people with dementia by family carers: representative cross sectional survey. British Medical Journal 338: b155.

Davenhill, R. (2007) Looking into later life: A psychoanalytic approach to depression and dementia in old age. London: Karnac Books.

de Vugt, M.E. \& Verhey, F.R. (2013) The impact of early dementia diagnosis and intervention on informal caregivers. Progress in Neurobiology 110: 54-62.

Evans, S. (2008) 'Beyond forgetfulness': How psychoanalytic ideas can help us to understand the experience of patients with dementia. Psychoanalytic Psychotherapy 22(3): 155-176.

Feast, A., Orrell, M., Charlesworth, G. Melunsky, N., Poland, F., \& Moniz-Cook, E. (2016) Behavioural and psychological symptoms in dementia and the challenges for family carers: systematic review. British Journal of Psychiatry 208: 429-434.

Feast, A., Orrell, M., Russell, I., Charlesworth, G., \& Moniz-Cook, E. (2017) The contribution of caregiver psychosocial factors to distress associated with behavioural and psychological symptoms in dementia. International Journal of Geriatric Psychiatry 32(1): 76-85.

Fonagy P., \& Allison, E. (2014) The role of mentalizing and epistemic trust in the therapeutic relationship. Psychotherapy 51: 372-280. 
Fonagy, P., Gergely, G., Jurist, E.L., \& Target, M. (2002) Affect regulation, mentalization, and the development of the self. New York: Other Press.

Gallagher, E., \& Rickenbach, E. H. (2019) Perceptions of couplehood among communitydwelling spousal caregivers. Aging \& Mental Health

https://doi.org/10.1080/13607863.2019.1594168

Garner, J. (2004) Identity and Alzheimer's Disease. In Kelleher D., Leavey G. (Eds) Identity and Health (pp.59-77). London, Routledge.

Gaugler, J.E., Roth, D.L., Haley, W.E. \& Mittelman, M.S. (2011) Modeling trajectories and transitions: Results from the New York University caregiver intervention. Nursing Research 60(Suppl): S28- S37.

Hiel, L., Beenackers, M. A., Renders, C. M., Robroek, S. J., Burdorf, A., \& Croezen, S. (2015) Providing personal informal care to older European adults: Should we care about the caregivers' health? Preventive Medicine 70: 64-68.

Kitwood, T., \& Bredin, K. (1992) Towards a theory of dementia care: personhood and wellbeing. Ageing \& Society 12(3): 269-287.

Lemma, A., Target, M. \& Fonagy, P. (2011) Brief Dynamic Interpersonal Therapy: A Clinician's Guide. Oxford: Oxford University Press.

Loboprabhu, S., Molinari, V. \& Lomax, J. (2007) The transitional object in dementia: Clinical implications. International Journal of Applied Psychoanalytic Studies 4: 144-169.

Long, K.H., Moriarty, J.P., Mittelman, M.S., \& Foldes, S.S. (2014). Estimating the potential cost savings from the New York University Caregiver Intervention in Minnesota. Health Affairs 33(4): 596-604. 


\begin{abstract}
Luengo-Fernandez, R., Leal, J., \& Gray, A. (2010) Dementia 2010: The economic burden of dementia and associated research funding in the United Kingdom. Cambridge: Alzheimer's Research Trust.
\end{abstract}

McCormack, L., Tillock, K. \& Walmsley, B.D. (2017) Holding on while letting go: Trauma and growth on the pathway of dementia care in families. Aging \& Mental Health 21(6): 658-667.

Malloy, L. (2009) Thinking about dementia-a psychodynamic understanding of links between early infantile experience and dementia. Psychoanalytic Psychotherapy 23(2): 109120.

McEvoy, P., \& Bellass, S. (2017) Using drawings as a reflective tool to enhance communication in dementia care. Nursing Standard 31(19): 46-52.

Mittelman,M.S., Roth,D.L., Coon, D.W. \& Haley, W.E. (2004) Sustained benefit of supportive intervention for depressive symptoms in caregivers of patients with Alzheimer's disease. American Journal of Psychiatry 161(5): 850-6.

Mittelman, M.S., Haley, W.E., Clay,O.J. \& Roth, D.L. (2006) Improving caregiver wellbeing delays nursing home placement of patients with Alzheimer disease. Neurology 67(9): 1592-9.

Morris, L., Mansell, W., Williamson, T., Wray, A., \& McEvoy, P. (2018) Communication Empowerment Framework: An integrative framework to support effective communication and interaction between carers and people living with dementia. Dementia: The International Journal of Social Research and Practice doi: org/10.1177/1471301218805329

Parkinson, M., Carr, S. M., Rushmer, R., \& Abley, C. (2016) Investigating what works to support family carers of people with dementia: a rapid realist review. Journal of Public Health 39(4): e290-e301. 
Piiparinen, R. \& Whitlatch, C.J. (2011) Existential loss as a determinant to well-being in the dementia caregiving dyad: A conceptual model. Dementia: The International Journal of Social Research and Practice 10(2):185-201.

Prince, M., Prina, M., \& Guerchet, M. (2013) World Alzheimer report 2013: Journey of caring. An analysis of long-term care for dementia. London: Alzheimer's Disease International.

Ramsay-Jones, E. (2015) Careful Engagement: Can the work of Ettinger, Klein and Bion help us to understand the relational field in dementia care? Psychodynamic Practice 21(3): 241253.

Ramsay-Jones, E. (2019) Holding Time: Human Need and Relationships in Dementia Care. Free Association Books: Stanmore.

Reddy, V. (2008) How infants know minds. Cambridge, MA: Harvard University Press.

Richardson, J.T., Lee, J.S., Weger, B. M., \& Grossberg, T. G. (2013) Caregiver health: Health of caregivers of Alzheimer's and other dementia patients. Current Psychiatry Reports, 15(367). Available at: https://link.springer.com/article/10.1007/s11920-013-0367-

Roth, D. L., Fredman, L., \& Haley, W. E. (2015) Informal caregiving and its impact on health: A reappraisal from population-based studies. The Gerontologist 55(2): 309-319.

Sabat, S. R. (2018) Alzheimer's Disease and Dementia: What Everyone Needs to Know ${ }^{\circledR}$. New York: Oxford University Press.

Santulli, R.B., \& Blandin, K. (2015) The emotional journey of the Alzheimer's family. Lebanon, NH: Dartmouth College.

Shai, D., \& Fonagy, P. (2014) Beyond words: Parental embodied mentalizing and the parent infant dance. In M. Mikulincer, \& P.R. Shaver (eds.), Nature and formation of social connections: From brain to group (pp. 185-203). Washington, DC: American Psychological Association. 
Stern D. (2004) The Present Moment in Psychotherapy and Everyday Life. London: Norton \& Company Ltd.

Taylor, J.S. (2008) On recognition, caring, and dementia. Medical Anthropology Quarterly 22(4): 313-335.

Tom, S.E., Hubbard, R.A., Crane, P.K., Haneuse, S.J., Bowen, J., McCormick, W.C. et al., (2015) Characterization of dementia and Alzheimer's disease in an older population: updated incidence and life expectancy with and without dementia. American Journal of Public Health 105(2): 408-413.

Tschanz, J.T., Piercy, K., Corcoran, C.D., Fauth, E., Norton, M.C., Rabins, P.V. et al., (2013) Caregiver coping strategies predict cognitive and functional decline in dementia: the Cache County dementia progression study. The American Journal of Geriatric Psychiatry 21(1): 5766.

World Health Organization (2012) Dementia: A Public Health Priority. Geneva: World Health Organization.

Wray, A. (2016) Mechanisms of conflict and aggression in the dementia context. Journal of Language Aggression and Conflict 4(1): 115-141. 


\begin{tabular}{|c|c|}
\hline Non-Mentalizing States of Mind & Mentalizing States of Mind \\
\hline $\begin{array}{l}\text { Carers defensively insist they are coping when they are } \\
\text { overwhelmed by emotions that are too much to bear. }\end{array}$ & $\begin{array}{l}\text { Carers able to acknowledge vulnerability. Conscious } \\
\text { of grief, guilt and regrets without being emotionally } \\
\text { overwhelmed. }\end{array}$ \\
\hline $\begin{array}{l}\text { Carers unable to pay attention to their state of mind } \\
\text { due to high levels of anxiety and the need to block out } \\
\text { painful experiences. }\end{array}$ & $\begin{array}{l}\text { Carers are curious about their own and other } \\
\text { people's states of mind; recognising that they are } \\
\text { complex and changeable. }\end{array}$ \\
\hline $\begin{array}{l}\text { Carers think that they know for certain what person } \\
\text { with dementia is thinking or feeling or that they do not } \\
\text { know what the person with dementia is thinking or } \\
\text { feeling at all. }\end{array}$ & $\begin{array}{l}\text { Carers can make informed judgements about the } \\
\text { subjective experience of the person with dementia, } \\
\text { but do not presume to know for certain what they are } \\
\text { thinking or feeling. }\end{array}$ \\
\hline $\begin{array}{l}\text { Carers are blind to trigger points and react without } \\
\text { thinking in the heat of the moment. Quick to feel sense } \\
\text { of personal rejection. }\end{array}$ & $\begin{array}{l}\text { Carers are aware of own trigger points and able to } \\
\text { acknowledge how own emotions and motivations } \\
\text { colour response to contentious issues. }\end{array}$ \\
\hline $\begin{array}{l}\text { Carers engage in actions without considering the impact } \\
\text { that they may have on state of mind of the person with } \\
\text { dementia. For example, repeatedly correcting } \\
\text { understandings that depart from 'true' facts. }\end{array}$ & $\begin{array}{l}\text { Carers think through the emotional impact of their } \\
\text { actions on person with dementia and make flexible } \\
\text { accommodations that open up opportunities for } \\
\text { positive engagement. }\end{array}$ \\
\hline
\end{tabular}

Table 1. The difference between non-mentalizing and mentalizing states of mind 
Enhancing the capacity to mentalize may help to increase the emotional resilience of family carers by helping to:

- Identify the feeling states and intentions that their spouse or parent with dementia maybe trying to communicate to them

- Sustain their capacity for empathic attunement

- Relate to the person with dementia as an intentional agent

- Label and accept their own feelings

- Avoid problematic relational positions such as distancing, task-focused responding or over-intrusive involvement

Table 2. Potential Benefits of Using Mentalization-Based Understandings 

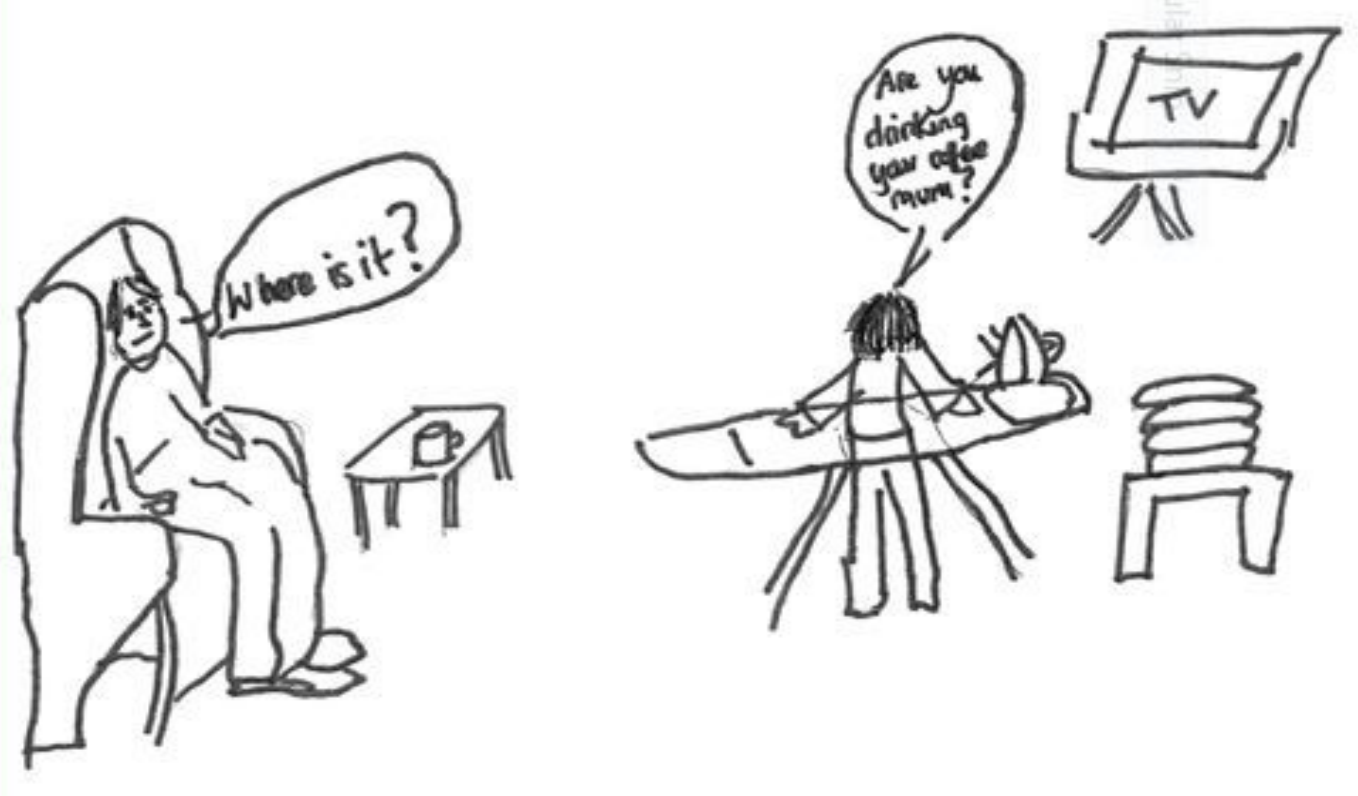

Figure 1. Jenny's Sketch 